\title{
Speakers use more redundant references with language learners: Evidence for communicatively-efficient referential choice
}

\author{
Shira Tal 1,3, Eitan Grossman², Hannah Rohde and Inbal Arnon ${ }^{4}$ \\ ${ }^{1}$ Department of Cognitive Sciences, The Hebrew University of Jerusalem \\ ${ }^{2}$ Department of Linguistics, The Hebrew University of Jerusalem \\ 3 Department of Linguistics and English Language, University of Edinburgh \\ 4 Department of Psychology, The Hebrew University of Jerusalem
}

\begin{abstract}
Author Note
Correspondence concerning this article should be addressed to Shira Tal, Centre for Language Evolution, School of Philosophy, Psychology and Language Sciences, University of Edinburgh, 3 Charles Street, Edinburgh, EH8 9AD, United Kingdom. E-mail address:

stal@ed.ac.uk
\end{abstract}

\section{Supplementary material}

https://osf.io/zjrsm/ 


\begin{abstract}
According to the communicative efficiency hypothesis, speakers should produce more linguistic material when comprehension difficulty increases. Here, we investigate a potential source of comprehension difficulty - listeners' language proficiency - on speakers' productions, using referential choice as a case study. Referential choice is influenced by communicative efficiency: pronouns are used less than full noun phrases (NPs) for less predictable referents (Tily \& Piantadosi, 2009). However, the extent to which it is influenced by the listener is debated. Here, we compare participants' descriptions of the same picture book to children, adult L2 learners and adult native speakers. We find that speakers use more full NPs when their interlocutors are learners - child and adult learners alike, illustrating an effect of listeners' proficiency (regardless of age) on production choices. Importantly, the increased use of full NPs relative to pronouns is found controlling for discourse-related differences (e.g., previous mention), suggesting a direct relation between listeners' perceived language proficiency and referential choice.

Keywords: reference, efficient communication, redundancy, child-directed speech, foreigner-directed speech
\end{abstract}




\section{Speakers use more redundant references with language learners: Evidence for communicatively-efficient referential choice}

It has long been argued that language use is governed by principles of efficient communication (Jaeger \& Buz, 2017; Pate \& Goldwater, 2015; Piantadosi et al., 2011a; Zipf, 1949). Research on language production has investigated how speakers balance the opposing pressures of minimizing production effort on the one hand and maximizing understandability on the other hand. If speakers efficiently trade off these pressures, they should reduce effort when possible, such that more predictable elements will be described with less linguistic material1 (Aylett \& Turk, 2004; Levy \& Jaeger, 2007; Pate \& Goldwater, 2015; Zipf, 1949). Indeed, a growing body of evidence shows that speakers' productions adhere to this principle: more predictable elements are more likely to be reduced or omitted (Aylett \& Turk, 2004; Cohen Priva, 2015; Frank \& Jaeger, 2008; Jaeger, 2010; Kravtchenko, 2014; Kurumada \& Jaeger, 2015; Levy \& Jaeger, 2007; Mahowald, Fedorenko, Piantadosi, \& Gibson, 2013; Pate \& Goldwater, 2015; Piantadosi et al., 2011; Tily \& Piantadosi, 2009). For example, English speakers are more likely to produce the optional complementizer that (e.g., I confirmed (that) I like her), when the complement clause is less predictable given the preceding verb (as is the case with confirmed). In other words, when possible, speakers use fewer or shorter elements to convey a more predictable message. This tendency was identified and described by Zipf (1949) as the Principle of Least Effort and by Grice (1975) as the Maxim of Clarity. In information-theoretic terms, speakers aim to minimize redundancy in their productions: they omit or reduce linguistic material when that is possible without changing the message.

${ }^{1}$ Throughout this paper, in line with the common terminology in the literature (Gibson et al., 2019), we operationalize minimizing redundancy as using less linguistic material. Note that definition does not necessarily capture acoustic redundancy. 
Importantly, speakers are not always predicted to avoid redundancy. According to the communicative efficiency hypothesis, increasing redundancy can be efficient if it helps prevent communication failures. In particular, speakers should produce 'costlier' signals (i.e., containing more linguistic material) when understandability is at risk. Theoretically, different factors can undermine understandability (see discussion in Pate \& Goldwater, 2015): predictability of the linguistic message itself, properties of the environment (e.g., noisy vs. quiet), and comprehension difficulties of the listener. Many existing studies demonstrate the impact of the first two factors on increased redundancy. Speakers tend to use more linguistic material when the conveyed meaning is unpredictable in context (Aylett \& Turk, 2004; Kurumada \& Jaeger, 2015; Levy \& Jaeger, 2007; Mahowald et al., 2013). For example, less predictable elements tend to be articulated more slowly than more predictable elements (e.g., nine is produced faster as part of the proverb a stitch in time saves nine than in the sentence the number you will hear is nine, Lieberman, 1963). Additionally, various studies document the impact of the environment on redundancy. For example, talkers provide more acoustic information in the presence of background noise (Lombard, 1911; Summers, Pisoni, Bernacki, Pedlow, \& Stokes, Michael, 1988; Zhao \& Jurafsky, 2009).

However, the impact of listeners' comprehension difficulty on increased redundancy has received less attention. There is ample evidence that speakers are aware of their interlocutors' knowledge and general characteristics and that they modify their speech accordingly - a phenomenon known as audience design (Ariel, 1990; Arnold, 2008; Brennan \& Hanna, 2009; Chafe, 1994; Clark \& Murphy, 1983; Heller et al., 2012; Isaacs \& Clark, 1987; Lockridge \& Brennan, 2002). From the perspective of communicative efficiency, this modification should lead speakers to increase redundancy when their interlocutors seem to have comprehension difficulty. In line with this reasoning, several studies demonstrate that speakers use more linguistic material in response to local instances of comprehension difficulty (Buz et al., 2016; Lockridge \& Brennan, 2002; Roche et al., 2013). For example, speakers tend to use longer pronunciations when their 
listeners are inattentive (Rosa et al., 2015). Importantly, speakers modify their speech not only on the basis of local indications of misunderstandings, but also based on global estimations of their interlocutors' knowledge state (Arnold, 2008; Bannon et al., 2020; Isaacs \& Clark, 1987; Loy \& Smith, 2020). For instance, speakers are more likely to adopt the syntactic structures used by interlocutors with lower language proficiency than ones with higher language proficiency (Loy \& Smith, 2020). These studies show that global interlocutor properties can impact speakers' production choices (e.g., the choice between one construction and another), but do not directly test the impact of perceived listener proficiency on increasing redundancy.

One way to explore this issue is by looking at the difference between child-directed speech (CDS) - which is inherently directed to lower proficiency learners - and adult-directed speech (ADS). Comparing redundancy between CDS and ADS can shed light on the impact of listeners' perceived proficiency on speakers' increased linguistic material. Several recent studies, mostly in the domain of phonetics, document such differences (Pate \& Goldwater, 2015; Tippenhauer et al., 2020; Uther et al., 2007). For example, adults reduce the phonetic duration of more predictable words to a smaller extent when talking to infants compared to adults (Pate \& Goldwater, 2015; Tippenhauer et al., 2020). Additionally, a recent study has tested the impact of the interlocutor on increased redundancy by looking at infant-directed speech (IDS) developmentally (Tal et al., 2021): if speakers modify redundancy depending on proficiency, then they should speak less redundantly with older (and more proficient) children. Using a global measure of redundancy that captures the average degree of word and multiword repetitions, Tal et al. (2021) found that IDS becomes less redundant as infants grow older, suggesting that speakers use more linguistic material when conversing with interlocutors in earlier stages of learning.

Taken together, these studies are consistent with the prediction that listeners' apparent language proficiency will impact the redundancy in speakers' productions. However, they leave several questions unanswered. The first is whether the modification in redundancy in response to listener proficiency applies across different levels of linguistic analysis. Current findings focus on 
the articulatory domain (Pate \& Goldwater, 2015; Tippenhauer et al., 2020; Uther et al., 2007) or on global estimates of redundancy (Tal et al., 2021). If listeners' language proficiency impacts redundancy broadly, this should be evident also in other language domains, including in the domains of morphology, syntax, and discourse, which are affected by communicative efficiency (Aylett \& Turk, 2004; A. F. Frank \& Jaeger, 2008; Kravtchenko, 2014; Kurumada \& Jaeger, 2015; Levy \& Jaeger, 2007; Mahowald et al., 2013; Tily \& Piantadosi, 2009). The second question is whether the increase in redundancy is unique to conversing with child learners, or whether it will also be found when conversing with less proficient adult learners. Existing findings mainly look at speech directed to child learners, who differ from adults not only in their language proficiency, but also in other cognitive abilities. Differences in redundancy between speech directed to younger infants and speech directed to older children and adults could therefore reflect adaptation to young children's unique cognitive and communicative needs (Fernald \& Simon, 1984; Werker et al., 1994), rather than to their lower language proficiency.

If, however, increased redundancy is strictly driven by listeners' language proficiency, then this tendency should also be found in speech directed to adult learners. In line with this reasoning, speech directed to adult learners - often called foreigner-directed speech - is regarded as a special register with unique characteristics (Ferguson, 1975; Long, 1983; Wooldridge, 2001). Foreignerdirected speech has several characteristics in common with CDS which could make it more redundant than adult-to-adult speech. Among other properties, it is characterized by having a slower speech rate (Rodriguez-Cuadrado et al., 2017), simpler sentences (Long, 1983) and more repetitions (Ramamurti, 1980; Wooldridge, 2001). Another piece of evidence for redundancy in speech directed to non-native speakers comes from comparing the amount of words used by native speakers as opposed to non-native speakers in a conversation (Bortfeld \& Brennan, 1997). When looking at the collaborative amount of words used by dyads of native and non-native speakers, native speakers produce higher portion of words compared to non-native speakers. Bortfeld and Brennan (1997) suggest this may reflect native speakers' attempt to ease the burden 
placed on non-native speakers by uttering more words themselves, in order to facilitate successful communication. On the other hand, speakers may not increase the redundancy in their speech, or do so to a lesser degree, when talking to adult learners: despite being learners, adult learners have similar cognitive capacities to those of adult native speakers, and might be perceived as more competent, in spite of their low proficiency level in the language in question. Speakers might therefore rank understandability higher than production effort only when conversing with child learners.

Here, we test the impact of conversing with non-proficient listeners, children or adults, on the redundancy in speakers' productions. If speakers modify the trade-off between understandability and effort on the basis of the perceived difficulty of their interlocutors, then speech directed to any type of learner should be more redundant compared to that directed to a proficient listener. Alternatively, if speakers modify this trade-off only when speaking to child learners, then we should see increased redundancy in speech directed to child learners, but not (or less so) in speech directed to adult learners. We test this using referential choice (the choice between pronouns and longer referents) as a case study since this is a domain where the impact of the listener is heavily debated. We find that speakers use more redundant referents when talking to both child and adult learners compared to proficient speakers.

\section{Referring expressions}

Speakers have multiple ways to refer to entities in the world. For example, when referring to the same individual, they can use a full noun phrase (NP) such as "The Vice President", a proper name, such as "Kamala Harris", or a pronoun, such as "she”. Unlike full NPs and proper names, pronouns are underspecified and have the potential to be more ambiguous. This raises the question of why and under what circumstances they are preferred (Arnold \& Zerkle, 2019). One advantage of pronouns is that they are shorter than full NPs (Arnold \& Zerkle, 2019; Tily \& Piantadosi, 2009) and possibly easier to produce (Van der Meulen et al., 2001; Vogels et al., 2015, though see Arnold \& Zerkle, 2019). Pronouns can therefore convey the same (or a very similar) 
message using less linguistic material (Tily \& Piantadosi, 2009). From the perspective of communicative efficiency, pronouns should be used less when understandability is at risk. This prediction is supported by several lines of evidence. Tily and Piantadosi (2009) had participants read fragments of texts, and guess which referent would be mentioned next. Participants' guesses were taken as estimates of the predictability of the referent and compared to the actual referent used in the text. In line with the communicative efficiency prediction, pronouns were found less when it was harder to guess the referent. In other words, pronouns were used less for less predictable referents (Tily \& Piantadosi, 2009). This tendency was also replicated in a computational model of reference (Orita et al., 2015).

That said, there is also competing evidence that speakers' pronoun production remains unaffected by predictability of the referent, and is instead driven primarily by the status of the referent as the discourse topic (Rohde \& Kehler, 2014, see also Givón, 1983; Grosz, Joshi, \& Weinstein, 1995; Lambrecht, 1994). For example, Rohde and Kehler find that the rate of pronominalization increases when the referent is more topical, but does not vary when the referent is more likely to be re-mentioned and therefore more predictable (though see Rosa \& Arnold, 2017). One reason for this may be that estimating topichood is something that a speaker can assess within their own model of the discourse, whereas estimating who the listener predicts for next mention requires a more computationally challenging listener-oriented perspective. Another piece of evidence suggesting that pronoun production is sensitive to speaker-oriented pressures comes from results showing that speakers produce fewer pronouns when the discourse contains multiple referents, even in discourse contexts where the use of a pronoun would be unambiguous to a listener (Arnold \& Griffin, 2007).

Taken together, the findings paint a mixed picture regarding the extent to which speakers' pronoun use is influenced by properties of the listener. Then again, referential choice has been shown to be influenced by one type of listener difficulty - lack of shared knowledge. Bard and Aylett (2004) analyzed speakers' referring expressions for landmarks, elicited using the Map Task 
(Bard et al., 2000). In this task, players describe routes between landmarks to each other: while some landmarks appear in both maps, others do not. Bard and Aylett (2004) found that referential choice was influenced by shared knowledge: when listeners and speakers did have a shared prior experience with the map, or when landmarks did not appear on both players' maps, speakers were less likely to use pronouns. These findings indicate that speakers are less likely to use pronouns when there are local risks to understandability.

Here, we investigate the impact of the listener's overall perceived difficulty on referential choice. We test this for both child learners and adult learners. There is some evidence to support the idea that speakers use more redundant references when conversing with both types of learners. First, one of the unique properties of IDS is a phenomenon known as "mommy deixis" (Durkin et al., 1982; Hyams, 2008), where caregivers substitute first and second pronouns with names and full NPs (e.g., "you want mummy to put back”, Durkin et al., 1982). This pattern is typically reserved for pronouns referring to the speaker, though it is not clear how wide-spread it is in IDS. Additional suggestive evidence come from caregivers' tendency to repeat full lexical forms when talking to young children (e.g., Where are your toes? Show me your toes. Come and show me your toes, Tal \& Arnon, 2018; Waterfall, 2006, see also Bortfeld \& Morgan, 2010). There is also some evidence for pronouns being dispreferred in conversations with adult learners. A recent study investigated speakers' adaptation to the referring expressions used by native and non-native interlocutors. This study found a priming effect for referential choice (participants were more likely to produce full NPs following a full NP prime compared to a pronoun prime) and a trend - though not a significant one - suggesting speakers might produce more full NPs when conversing with non-native speakers than with native speakers (Loy et al., 2020).

\section{The current study}

We test the impact of the listeners' proficiency - both child and adult learners - on speakers' use of pronouns vs. longer referring expressions (full NPs and names) in describing the same picture book in Hebrew. To investigate the impact of child learners, we look at CDS 
developmentally, treating younger children as less proficient than older ones (Tal et al., 2021). While there are studies looking at referential choice in CDS (Allen et al., 2015; Bortfeld \& Morgan, 2010; Hughes \& Allen, 2013, 2015; Rohde \& Frank, 2014), the current study is the first to ask how care-givers' referential choices change as a function of children's age in the same conversational setting (i.e. while conversing about similar topics). To investigate the impact of adult learners, we compare speech directed to native speakers and speech directed to non-native speakers. We ask (a) whether speakers increase redundancy when talking to less proficient speakers, and (b) whether they do so when conversing with both child and adult learners. In Study 1 we investigate parents' referential choices when telling a story to child learners between the ages of 1-6 years. If speakers' choices are influenced by listener proficiency, then parents should be less likely to use pronouns (as opposed to longer referents) when their children are younger. In Study 2, we investigate speakers' referential choices when telling the same story to adult learners and adult native-speakers. If speech to less proficient speakers in general is more redundant, then speakers should be also less likely to use pronouns (as opposed to longer referents) when their interlocutors are non-native speakers. Finally, if referential choice is not significantly influenced by listeners' proficiency level, then referential choice should not be influenced by either type of learner. We use book reading since it is a natural activity (compared with experimentally-defined referential tasks). More importantly, unlike naturalistic speech, book reading allows us for control over changes in topics of conversation.

As alluded to earlier, referential choice is influenced by a variety of factors. For example, pronouns are preferred for discourse-old referents (Chafe, 1976; in CDS: Guerriero et al., 2006; Hughes \& Allen, 2015), second and subsequent mentions (Ariel, 1990; Gundel, Hedberg, \& Zacharski, 1993; in CDS: Rohde \& Frank, 2014), subjects (Brennan, 1995) and animate referents (Fukumura \& Van Gompel, 2011). Pronouns are dispreferred in the presence of a referential competitor in the preceding linguistic context (Arnold \& Griffin, 2007) and visual context (Fukumura et al., 2010), and when there is similarity between discourse entities (Fukumura et al., 
2011). In the present study, in order to investigate the impact of the interlocutor on speakers' referential choice, we aimed to reduce the impact of discourse-related factors. To do so, we created a novel corpus in which all participants described the same picture book to different types of interlocutors (adult native speakers, adult L2 learners, children ages 1-6 years old). Having participants tell addressees the same story keeps the visual and the narrative constant, and arguably reduces differences in all the above-mentioned factors. Importantly, we also controlled for local discourse status of the referents by annotating whether they appeared in the previous clause and in what syntactic role (subject vs. non-subject).

\section{Data availability}

The data and analysis code for this study are openly available for download on OSF (DOI https://osf.io/zjrsm/).

\section{Study 1 - child-learner study}

\section{Method}

\section{Participants}

27 parents and children participated in the study (children's age range: $1 ; 4-5 ; 6 y$, mean age: 3;2y, 15 boys and 13 girls). There were 28 children since one of the parents read the story to her twins: age 2;6, both girls). One dyad of parent and child was excluded from further analysis since they stopped the experiment mid-way. All children and parents were visitors at the Bloomfield Science Museum in Jerusalem. They were recruited for this study as part of their visit to the Israeli Living Lab in exchange for a small reward. Parental consent was obtained for all children. All children and parents were native Hebrew speakers, the language the study was conducted in.

\section{Materials}

The picture book we used was Frog, where are you? (Mayer, 1969). The book tells the story of a boy and his dog who are searching for their missing pet frog, and encounter various 
animals during their quest. This book has been used extensively in cross-linguistic and developmental work (Berman, 1988; Berman \& Slobin, 1994; Miller et al., 2006).

\section{Procedure}

The procedure was modeled after Berman (1988), with slight adaptations. Parents were told they were about to participate in a study designed to investigate storytelling. They were instructed to go over the whole book by themselves, and then tell the story to their children. It was emphasized that the storytelling would take place with the book, so there was no need to memorize the story. After they finished looking through the whole book, the parents and children were escorted to a private section in the Living Lab, and were seated in front of a table with the book on it. Parents were instructed to tell the story as naturally as possible, with the exception of trying not to ask the child any questions. Interactions were audio- and video-recorded. Parents wore a clip-on Shure microphone (BLX14E/CVL) that was wirelessly connected to a Panasonic HC-V76 full HD camcorder. The camera was aimed at the parents' and children's hands and at the book (which was positioned in a fixed place). Once the parent and the child were ready, the experimenter started filming and recording and left the child and parent to themselves. The parent was instructed to call the experimenter once the story was finished.

\section{Transcription and coding of dependent variables}

The films were transcribed by trained research assistants. Our variable of interest was the reference type used for two main characters - the boy and the dog. We focused on these characters since the rest of the characters (except for the frog, which we elaborate on next) were only mentioned a handful of times. We excluded references for the frog character since they often appeared as part of a quote, as in cases where the boy and the dog were calling out for it (often repeating the name of the book by calling "Frog, where are you?"). These are not circumstances where pronouns are appropriate, and therefore are not suitable for our question. For our analysis, we extracted all mentions of the boy and the dog where a parent used a pronoun, full NP, or name (some parents invented names for the different characters). Pronouns were extracted manually 
by research assistants, whereas full NPs (including names) were extracted from the transcriptions automatically (research assistants coded once the names chosen by participants, based on which all name referents were automatically extracted). Plural references (e.g., they or "the boy and the dog”, referring to both characters) were counted once, as referring to a boy\&dog referent. Plural references that referred to either the boy or the dog alongside other characters (e.g., "the boy and the deer") were not included in the analysis $(\mathrm{N}=5)$. First and second person pronouns (e.g., $I$, you), as well as references that were used as part of quotes were excluded from analysis ( $\mathrm{N}=54)$, since they cannot be replaced with full NPs (if a speaker adopts the perspective of one of the characters by referring to it as $I$, full NPs like "the dog" are not possible alternatives). Genitive pronouns (e.g., his) were also excluded from analysis $(\mathrm{N}=61)$, since these pronouns were often part of other references (e.g., he looked for his frog all over the room). Similarly, genitive noun phrases (e.g., the child's frog) were also excluded from analysis $(\mathrm{N}=7)$. In addition, instances where a noun and a name appeared together as one reference (e.g., Max the dog) were counted only once. Eventually, there were 829 pronoun references and 564 longer references (full NPs and names).

For each participant, we looked at all the references used to refer to the two main characters. If speakers adapt the redundancy in their speech to their interlocutors' language level, then they should use fewer NPs and more pronouns with older addressees. Importantly, as already mentioned, referential choice is strongly affected by discourse status (Chafe, 1976; Guerriero et al., 2006; Hughes \& Allen, 2015; Rosa \& Arnold, 2017). Specifically, referents mentioned in the previous clause - and in particular in the subject position of a previous clause - are more likely to be pronominalized (Arnold, 2010; Gundel et al., 1993). This means that any impact of addressee's proficiency on referential choice could reflect an underlying difference in discourse strategies in speech directed to children of different ages. For example, parents of younger children might move between the description of different characters (e.g., Look at this dog. And here is the frog. The dog seems happy) whereas parents of older children might describe 
characters in a more sequential fashion (e.g., Look at this dog. The dog seems happy. And here is the frog). Such different discourse structures are predicted to yield differences in referential choice (regardless of proficiency), and may result in an indirect effect of proficiency where the listener's proficiency level impacts referential choice through the use of different discourse strategies $^{2}$. To control for this possibility, we coded each mention of the two characters for its "previous mention status": (a) whether it was mentioned by either speaker in the previous clause, and (b) if so, whether it was the subject of the previous clause or not. The coding was done manually by the first author, who is a native speaker of Hebrew. Clauses were defined as a combination of a predicate (full verb or nonverbal predicate) and its arguments, plus modifiers (Velupillai, 2012, p. 229). Cases where the referent did appear in the final clause, were coded for whether the character appeared in the subject position or not. Five references were excluded from this analysis since it was not possible to determine their previous mention status. See Table 1 for examples of clauses. The full annotated data is available at https://osf.io/zjrsm/.

Importantly, the correct way to treat plural references with respect to their previous mention status is not straightforward. For example, plural references referring to two characters can have a previous mention of only one of the characters, as in Example 1A. Similarly, singular references, referring to just one character, can have a previous mention in a plural form, referring to both that character and an additional one, as in 1B. Finally, plural references for which both characters were mentioned in the previous clause can also vary: the previous mention can be a plural reference where both characters are referred to using the same reference, as in $1 \mathrm{C}$, or can be made with two separate singular reference, as in 1D.

\footnotetext{
${ }^{2}$ We would like to thank an anonymous reviewer for raising this possibility and suggesting how we can explore it.
} 
1. Example sentences for previous mentions. References in question are underlined.

A. The boy woke up. The boy and his dog went out.

B. The boy and the dog were sad. The boy went outside.

C. The boy and the dog woke up. They couldn't find the frog.

D. The boy hugged the dog. They started looking for the frog.

Importantly, speakers can interpret a composite of references as one given set, even when mentioned separately, as in 1D (Brown-Schmidt et al., 2005). To account for these different possibilities, we adopted two coding schemes for previous mentions. The first coding scheme, henceforth, "two-level coding”, classified references as given or new. If a referent was mentioned in a previous clause, regardless of whether it was mentioned in the same or different NP in the previous clause, it was considered as given. For example, "they" in both $1 \mathrm{C}$ and $1 \mathrm{D}$ above would be considered as given. In all other cases the reference was classified as "new". Plural references for which only one of the referents was mentioned in a previous clause, as in $1 \mathrm{~A}$, were considered as "new".

The second coding scheme, which we call "three-level coding”, classified references for whether they were mentioned in a previous clause in the subject position, in a non-subject position, or not mentioned at all. Under this coding scheme, plural references were only classified as mentioned in a previous clause if they appeared in the same position. For example, under this coding scheme "they" in $1 \mathrm{C}$ would be considered as mentioned in a previous clause in a subject position, but in $1 \mathrm{D}$ it would be considered as not mentioned at all. Thus, this coding scheme differs from the previous one in two respects: 1 . Not treating alike plural references whose previous mention was in the same vs. different noun phrase, 2. Having three levels of "givenness": mentioned in subject position, mentioned in a non-subject position, and not mentioned. Note that in both of these coding schemes, singular references that have a previous mention as plurals (as 
in 1A) are classified as having no previous mention. As we note below (see footnote 3), the effects reported in both coding schemes still hold even if these references are classified as given.

\section{Results}

Figure 1 shows the proportion of using a full NP (rather than a pronoun) as a function of age and of previous mention status following the three-level coding scheme (i.e., whether the reference was mentioned in the previous clause, and if so, at what syntactic position). We used mixed-effect logistic regression models to examine the effect the addressee's age on participants' referential choice (here and in all subsequent models, we used the lme4 package in R software, Bates, Mächler, Bolker, \& Walker, 2015, and the maximum random effect structure justified by the data that converged, Barr, Levy, Scheepers, \& Tily, 2013). We used two models to investigate our two previous mention coding schemes. The first model had reference type (full NP vs. pronoun) as a dependent variable and the following fixed effects: age (in months, mean-centered), previous mention status according to the two-level coding scheme (new vs. given; sum coded), character (boy, or dog or boy\&dog; sum coded), and interaction of age with previous mention status. In addition, the model included random intercepts for participants and by-participant random slopes for previous mention status (see Table 2 for the full model). As predicted, we found a significant effect of age on reference type: the use of longer NPs (rather than pronouns) decreased with the child's age, indicating that parents use less redundant references with older children $(\beta=-0.02, \mathrm{SE}=0.01, p=0.02)$. Additionally, we found an effect of pre-mention status: in line with previous work on discourse status (Arnold, 2010; Gundel et al., 1993), references were more likely to be full NPs when they were not mentioned in the previous clause $(\beta=0.83, \mathrm{SE}=0.09$, $p<0.001)$. We also found an effect of character type, indicating an effect of plurality: the boy\&dog entity was less likely to be referred to using a full NP. This finding may reflect the properties of the story: the child and the dog character look for the frog together throughout most of the story, going through a sequence of activities they both participate in. They therefore tend to be 
mentioned in plurality in subsequent clauses, making them more likely to appear in a pronoun form (Arnold, 2010; Gundel et al., 1993).

We used a second model to test the impact of our three-level coding scheme for previous mentions. The model had reference type (full NP vs. pronoun) as a dependent variable and the following fixed effects: age (in months, mean-centered), previous mention status according to the three-level coding scheme (previously mentioned as subject, previously mentioned not as subject, and not previously mentioned; sum coded), interaction of age with previous mention status, and character (boy, dog or boy\&dog; sum coded). The model additionally included random intercepts for participants (see Table 3 for the full model). Again, in line with our predictions, we found a significant effect of age on reference type: parents tended to use more pronoun (and less longer NPs) with older children $(\beta=-0.02, \mathrm{SE}=0.01, p=0.04)$. We found an effect of pre-mention status also in the three-level coding scheme: references were less likely to be full NPs when they were mentioned as subjects in the previous clause $(\beta=-0.92, \mathrm{SE}=0.11, p<0.001)$. This is in line with previous studies showing that references that are previously mentioned in the subject position are most likely to be pronouns (Arnold, 2010; Gundel et al., 1993). We again found an effect of character type, such that boy\&dog entity was less likely to be referred to using a full NP $(\beta=-1.458$, $\mathrm{SE}=0.13, p<0.001)$. Finally, we found an interaction between age and previous mention status, such that the effect of age on referential choice was least strong when the reference had a previous mention as a subject. In other words, the tendency to use pronouns after a previously mention subject was relatively similar when telling the story to children of different ages. The effect of the child's age was stronger when the reference was mentioned in a non-subject position and when it was not mentioned at all. 
Taken together, these results ${ }^{3}$ suggest that on top of other factors impacting referential choice, such as previous mentions, parents use more redundant references when talking to younger children.

\section{Discussion}

In line with our predictions, we found a decrease in parents' usage of full NPs with children's age, suggesting that parents use more redundant references (full NPs or names) when talking to younger children. Importantly, this effect was found even when the impact of previous mention status on referential choice was controlled for (operationalized in two different ways). These findings suggest that speakers are sensitive to the proficiency level of their interlocutors, and increase redundancy with less proficient interlocutors, in line with the communicative efficiency hypothesis (Buz et al., 2016; Jaeger \& Buz, 2017; Pate \& Goldwater, 2015) and previous developmental findings (Tal et al., 2021). Importantly, however, this study does not measure the effect of language proficiency directly. Rather, age serves as a proxy for proficiency. If indeed the listener's language proficiency impacts the redundancy in speech, then the effect of proficiency should be found regardless of age. Specifically, similar changes in redundancy should be found in speech directed to adult learners. To test this, we conducted Study 2, using the same procedure as Study 1, but now instead of looking at the way parents use referring expressions with their children, we investigated referring expressions of proficient adult speakers telling the story to either other proficient adult speakers, or to adult non-native speakers. If speech directed to nonproficient speakers is more redundant, then speakers should use more full NPs (and fewer pronouns) when their interlocutors are non-native speakers.

3 Recall that in both coding schemes, singular references that have a previous mention as plurals are classified as having no previous mention. The effects reported in both coding schemes remain significant even when these references are classified as given (or given in a specific slot, as in the second coding scheme). 


\section{Study 2 - adult-learner study}

Study 2 set out to investigate the impact of the listener's language proficiency on speakers' referential choice, when both the speaker and the listener are adults. We can contrast two different predictions. On the one hand, if the impact of the interlocutor on redundancy is strictly related to perceived language proficiency, then speech directed to adult learners should contain more redundancy than speech directed to adult proficient speakers. On the other hand, the adaptation seen for child learners might not stem from language proficiency per se, but rather from speakers' perception of children's more general cognitive development. If this is the case, then we should not find similar changes in speech directed to adult language learners.

\section{Method}

In this study two adults participated in the interaction. One of the adults was a naive participant, the other was presented as another participant, but was in fact a confederate. There were two types of confederates: one group of participants interacted with a native speaker of Hebrew (the language of the participants), and another group of participants interacted with a non-proficient Hebrew speaker (see details below). Confederate paradigms are common practice in studies of foreigner-directed speech and the impact of non-native speakers (Loy et al., 2020; Loy \& Smith, 2020; Rodriguez-Cuadrado et al., 2017).

\section{Participants}

Fifty-eight students at the Hebrew University (34 females and 24 males) participated in the study for course credit or payment. Subjects were all native Hebrew speakers. Subjects were assigned to one of two conditions: interacting with a confederate who is a learner (28 participants), and interaction with a confederate who is a native speaker (30 participants). Four participants were excluded from analysis for the following reasons. One participant used the same name for the boy and the dog in the story, making it impossible to decipher the correct referents (not only automatically but also manually); one participant decided, in contrast to the guidelines, to tell the listener the story without the picture book; two participants mentioned the dog only at 
the beginning, but then ignored its actions for the rest of the story. These exclusions left 54 participants (25 in the learner condition, 29 in the proficient speaker condition).

The learner confederate was a native English speaker, a beginner learner of Hebrew (the participants' language), with a noticeable accent. The proficient-speaker confederate was a native Hebrew speaker. Both confederates were males in their early twenties.

\section{Materials}

Same as Study 1.

\section{Procedure}

As in Study 1, participants were told they were about to participate in a study designed to investigate storytelling. The confederate was presented and treated by the experimenter as another participant who was likewise about to participate in the experiment. The session began with three introductory questions presented to the participant and the confederate by the experimenter: 1. What is your mother tongue? 2. For anyone who did not answer Hebrew in Question 1, which was always the case for the learner-confederate: When did you start to learn Hebrew? For the rest: So Hebrew is your first language? 3. How would you rate your Hebrew level, between 1-5? (1-no knowledge of the language, 5 - full knowledge of the language).

The answers given by the confederates were always the same. The learner confederate answered: 1. "English". 2. "Five months ago", uttered with a grammatical mistake in Hebrew. 3. "I know Hebrew about 2. I have a lot how to learn" (a literal translation of the original answer, which contained several grammatical mistakes). The proficient-speaker confederate answered: 1. "Hebrew" 2. "Yes". 3. "5".

Following these questions, the experiment was explained to both participants. They were told that one of the participants was going to tell a story, according to a picture book, to the other. It was presented as being arbitrarily determined that the (actual) participant would be the one telling the story to the confederate. It was emphasized that the story-telling should be in Hebrew. Finally, they were told the listener would be tested on the storyline afterwards. Then, the listener 
(the confederate) was asked to wait in the experiment room while the storyteller (the actual participant) was instructed to go over the whole book by themselves. When finished, the participant joined the listener in the experimental room - a private and quiet room. The two were seated close to each other, in front of a table with the book. While the experimenter prepared the camera for recording, the confederates (in both conditions) initiated casual small-talk asking the other participants which department they are from. The purpose of this small-talk was to give participants another chance to hear the confederates talk. Confederates said the same to all participants, and the learner confederate again spoke with some grammatical mistakes. After this short conversation, the experimenter interrupted to say the camera was ready. The interaction was audio- and video-recorded using a Panasonic HC-V76 full HD camcorder. The camera was aimed at the participant's hands and at the book (which was positioned in a fixed place). Once the participant and the confederate confirmed they were ready, the experimenter started the camera and left them alone. They were instructed to call the experimenter once the story was finished. Once the story-telling was over, the participant was asked to fill in a short debrief questionnaire, while the listener was instructed to wait in the experimental room before conducting a comprehension test on the storyline. The questionnaire included questions targeting how participants estimated the listener's Hebrew proficiency and the general aim of the study.

\section{Transcription and coding of dependent variables}

Same as Study 1. 14 first person pronouns, 146 genitive pronouns, 21 genitive NPs, and 36 plural references that referred to other characters (e.g., boy and owl) were excluded from analysis. The remaining references were 1268 pronoun references and 908 names or full NPs. As in Study 1, each mention of the two characters was annotated with respect to the previous clause: whether it was mentioned in the previous clause as a subject, not as a subject, or not mentioned at all. Previous mention status was then established for each reference using the same two coding schemes as in Study 1. Only three references were excluded from this analysis since it was not possible to determine their previous mention status. 


\section{Results}

First, we examined participants' responses to the debrief questionnaire, to see whether the confederates' proficiency was estimated correctly. Participants had to rate the listener's Hebrew rate on a scale between 1 and 5 . Participants who had a learner as a listener gave a mean rating of $2.56(\mathrm{SD}=0.65)$, while those who had a proficient speaker as a listener gave a mean rating of 4.93 $(\mathrm{SD}=0.26)$. A non-parametric Wilcoxon signed rank test confirmed this difference to be significant, indicating the learner's Hebrew level was indeed estimated as lower than that of the proficient-speaker's level ( $\mathrm{V}=723, p<0.0001)$. In addition, none of our participants guessed the confederates were not real participants.

Having established that participants estimated the proficiency levels of the confederates as expected, we next turned to see whether the confederates' proficiency level affected the types of references participants used. If speech directed to non-proficient speakers is more redundant, then participants should use fewer pronouns when they tell the story to the learner confederate. Figure 2 shows the proportion of using a full NP (rather than a pronoun) as a function of condition (confederate type) and of previous mention status following the three-level coding scheme. As is Study 1, we used two mixed-effect logistic regression models to examine the effect the addressee's proficiency, as well as local discourse status (operationalized in two ways), on participants' referential choice. The first model had reference type (full NP vs. pronoun) as a dependent variable, and the following fixed effects: condition (learner vs. proficient addressee, sum coded), previous mention status (given vs. new; sum coded), interaction of condition with previous mention status, and character (boy,dog and boy\&dog; sum coded). In addition, the model included random intercepts for participants and by-participant random slopes for previous mention status (see Table 4 for the full model).

We found a significant effect of condition on pronoun use: participants used more pronouns in the proficient-speaker condition, indicating they used less redundant references when their interlocutor was a proficient speaker $(\beta=-0.243, \mathrm{SE}=0.1, p=0.02)$. In addition, we 
found that references that were not mentioned in a previous clause were more likely to be longer NPs or names $(\beta=1.246, \mathrm{SE}=0.075, p<0.001)$. We also found an effect of character type. First, as in Study 1, they plural references (boy\&dog references) were more likely to be pronouns ( $\beta=-1.84$, $\mathrm{SE}=0.1, \mathrm{p}<0.001)$. Finally, we found that compared to the dog, the references used for the boy were more likely to be longer NPs $(\beta=0.3, \mathrm{SE}=0.08, p<0.001)$.

As in Study 1, we used a second model to test the impact of our three-level coding scheme for previous mentions. The model had reference type (full NP vs. pronoun) as a dependent variable and the following fixed effects: condition, previous mention status according to the threelevel coding scheme (previously mentioned as subject, previously mentioned not as subject, and not previously mentioned; sum coded), interaction of condition with previous mention status, and character (boy, dog or boy\&dog; sum coded). The model additionally included random intercepts for participants (see Table 5 for the full model). In this model as well we found an effect of condition on pronoun choice $(\beta=-0.235, \mathrm{SE}=0.1, p=0.04)$. Previous mention status, also using the three-level coding scheme, had an effect on referential choice: references more likely to be pronouns when they were previously mentioned as subjects $(\beta=-1.025, \mathrm{SE}=0.1, p<0.001)$ or not as subjects $(\beta=-0.565, \mathrm{SE}=0.1, p<0.001)$. Finally, we found the same effect character type on referential choice such that compared to the dog, references were less likely to be pronouns when they referred to the boy $(\beta=0.359, \mathrm{SE}=0.08, \mathrm{p}<0.001)$, and more likely to be pronouns when they referred to the boy and dog together $(\beta=-1.92, \mathrm{SE}=0.1, \mathrm{p}<0.001)^{4}$.

\section{Discussion}

As predicted, speakers used longer, more redundant, references (full NPs or names) when talking to non-native speakers as opposed to native speakers. As in Study 1, this effect was found

4 As in Study 1, the effects reported in both coding schemes remain significant even when these references are classified as given (or given in a specific slot, as in the second coding scheme). 
controlling for other factors impacting referential choice, using two different coding schemes for previous mentions. Importantly, these findings provide support for a direct impact of listeners' perceived language proficiency level on redundancy in speech. Taken together, speakers use more redundant references when talking to learners - child and adult learners alike. This suggests that the increased redundancy found in speech directed to child learners (Tal et al., 2021, Study 1) could not (only) be explained by young children's general cognitive abilities, but rather from their lower language proficiency.

\section{General Discussion}

According to the communicative efficiency hypothesis, speakers are predicted to increase redundancy in cases of comprehension difficulty (Jaeger \& Buz, 2017; Kurumada \& Jaeger, 2015; Pate \& Goldwater, 2015; Zipf, 1949). Following this reasoning, speakers should provide more linguistic material when talking to listeners that are more likely to misunderstand them. This is the typical state of affairs when conversing with language learners. Indeed, speakers modify their speech when talking to language learners (Loy \& Smith, 2020; Rodriguez-Cuadrado et al., 2017; Uther et al., 2007; Van Engen et al., 2010; Wooldridge, 2001). However, very few studies have investigated whether speakers adapt the redundancy in their speech when talking to learners compared to proficient speakers. Our study set out to ask whether speakers speak more redundantly when conversing with language learners, and whether they do so similarly for both adult and child learners. We used referential choice as a test case since previous work has shown it to be sensitive to communicative efficiency: pronouns are preferred over longer referents (full NPs and names) when the message is more predictable (Tily \& Piantadosi, 2009), and in local instances of comprehension difficulty (Bard \& Aylett, 2004; Tily \& Piantadosi, 2009). Expanding on this, our study set out to ask whether speakers use more redundant references when talking to less proficient language learners. To do so, we created a novel corpus designed for comparing speech directed to proficient speakers, adult and child learners. The corpus contains 
transcriptions of story-telling events, in which speakers describe the same picture book to different listeners.

In line with our predictions, we found that speakers tend to use more redundant references (fewer pronouns and more full NPs and names) when talking to learners - child and adult learners alike. Parents used more redundant references with younger children, suggesting they adapt the redundancy in their speech to their child's perceived proficiency. These results are compatible with recent findings showing that parents tend to speak more redundantly overall to their children when they are younger (Tal et al., 2021). Importantly, in both studies, age was used as a proxy for proficiency. It could be the case that parents adapt the redundancy in their speech to more general cognitive capacities that change with age, rather than language proficiency per se. In Study 2, we provide a more direct test of the impact of the listener's language proficiency on redundancy by looking at speech directed to adult learners. We found that speakers tend to use more redundant references when talking to adult non-native speakers than when talking to native speakers. These results suggest that speakers efficiently adapt the redundancy in their speech based on listeners' perceived language proficiency. Importantly, in both studies we found these results on top of the predicted impact of discourse patterns (Arnold, 2010; Gundel et al., 1993), even when using two different coding schemes for previous mentions. This suggests that speakers' tendency to use more redundant references when talking to less proficient speakers is not a result of discourse modifications that are known to affect pronominal use. Rather, it is an additional source of influence on referential choice.

The current findings have consequences for the role of audience design in referential choice. The extent to which speakers model the needs of their addressee when choosing referring expressions is heavily debated in the literature (Arnold, 2008; Arnold \& Zerkle, 2019; Bard \& Aylett, 2004; Fukumura \& Van Gompel, 2012). Results from various studies suggest speakers' referential choices are influenced by listener knowledge, in some, but not all, cases. For example, Fukumura and Van Gompel (2012) found that speakers tend to produce pronouns when the 
referent was mentioned before, regardless of whether the addressee has heard the preceding mention, suggesting that the choice of referring expression relies on the speaker's own knowledge, rather than the listener's knowledge. In contrast, Bard and Aylett (2004) and Fukumura (2015) found that referential choice is impacted by listeners' knowledge. Prima facie, our results lend support to the idea that referential choice is impacted also by listeners' knowledge, and not only by speakers' knowledge. Our results however seem compatible with a more nuanced suggestion, that takes both listener and speaker limitations into account. Specifically, it has been argued that speakers cannot always keep track of all sources of information available to the listener, and that consequently, in some cases referential choice cannot be adapted to listeners' changing knowledge (Bard \& Aylett, 2004). In these cases, only salient listener properties are predicted to influence referential choice (Bard \& Aylett, 2004). In line with this reasoning, estimating the listener's language proficiency seems to be such a salient property, one which is easily computed (typically once), without having to dynamically update it throughout the conversation, and that can subsequently impact referential choice, as we found. What specific properties of listeners lead speakers to assume lower proficiency (and influence referential choice as a result) is an open question that should be explored in future work.

The tendency to use more redundant references when addressing both child and adult learners has implications for recent proposals on the differential role of child and adult learners in processes of language change. A growing body of work suggests that the proportion of adult second-language learners in a language community has an effect on structural changes in the language. Specifically, languages spoken by a larger proportion of adult learners seem to become more morphologically simplified over time (Bentz et al., 2015; Bentz \& Winter, 2013; Dale \& Lupyan, 2012; Lupyan \& Dale, 2010; Trudgill, 2009; Wray \& Grace, 2007). This process is suggested to be mediated by speakers' linguistic adaptation to adult learners (Atkinson et al., 2018; S. Frank \& Smith, 2018; Loy \& Smith, 2020). A recent hypothesis proposes that the opposite is true for populations whose main language learners are children: child learners are predicted to 
benefit from redundancy while adult learners do not, leading to a decrease in redundancy for languages with many adult learners and a preservation of redundancy for languages with more child learners. This hypothesis is known as the Linguistic Niche Hypothesis (Dale \& Lupyan, 2012; Lupyan \& Dale, 2010). While not explicitly stated, this hypothesis rests on the assumption that speech directed to child learners should be more redundant, whereas speech directed to adult learners should not. Prima facie, our results seem to be at odds with this assumption: we found increased redundancy in speech directed to both types of learners. This suggests that speakers adapt their speech to both types of learners in the same way, by increasing redundancy. However, it is possible that the extent to which speakers adapt the redundancy in their speech is larger for child learners, in line with the Linguistic Niche Hypothesis. In the current study we could not compare the magnitude of the adaptation between both types of listeners, but this is an important question to pursue in future work.

Note, however, that when examining the current results with respect to theories of language change, there are important limitations to take into account. First, while the alternation between a pronoun and a longer referent accords with the communicative efficiency (and information-theoretic) notions of redundancy (Orita et al., 2015; Tily \& Piantadosi, 2009), this is not necessarily the type of redundancy examined in the Linguistic Niche Hypothesis5. Second, the current study provides a small snapshot for increased redundancy in speech directed to learners, that should be investigated for other types of redundancies as well. While speakers might use more redundant references when talking to both child and adult learners, other properties of speech might show a clear distinction between different types of learners. For example, phonetic properties of speech like shorter articulation for second mentions, which are arguably more

${ }^{5}$ The definition for redundancy in the paper (Text S9) is "the degree that grammatically encoded information specifies something that can be readily extracted from context or pragmatics". It is debatable whether the alternation between pronouns and longer references fits this definition. 
automatic (Arnold, 2008; Bard \& Aylett, 2004) might be influenced by conversing with child learners (Tippenhauer et al., 2020) but not with adult learners (Rodriguez-Cuadrado et al., 2017).

\section{Conclusion}

According to the communicative efficiency hypothesis, speakers should increase redundancy, i.e., produce more linguistic material, when comprehension difficulty increases. Here we investigate the impact of listeners' estimated proficiency on speakers' productions, using referential choice as a case study. Compared to proper names and full noun phrases, pronouns can convey similar content with less linguistic material. Accordingly, speakers use more longer referring expressions when the message is unpredictable (Tily \& Piantadosi, 2009) and when listeners lack relevant information (Bard \& Aylett, 2004). This study set out to test whether referential choice is also influenced by listeners' estimated proficiency. To test this, we created a novel corpus comparing participants' descriptions of the same picture book to child learners, adult learners and proficient speakers. We found that speakers used more redundant references when their interlocutors were learners - child and adult learners alike. These findings support the idea that referential choice is governed by efficient communication principles, show a direct relation between listeners' language proficiency and redundancy, and bear consequences for theories of language change based on accommodation to non-native speakers.

\section{Acknowledgments}

We wish to thank Henry Brice, Ram Frost, Limor Raviv, and Kenny Smith for helpful discussions. We also want to thank Rimon Alyagon Dar, Dani Beckman, Tali Cohen, Amir Efrati, Maya Mark, Maya Ravid, and Yael Tal for collecting, transcribing, and coding the data. We thank the Bloomfield Science Museum staff, and the children and parents who participated in the studies. This research was supported by the Israeli Science Foundation grant number 584/16 awarded to IA. ST was funded by the Mandel Scholion Center at the Hebrew University of Jerusalem. 


\section{References}

Allen, S., Hughes, M. E., \& Skarabela, B. (2015). The role of cognitive accessibility in children's referential choice (Issue September). https://doi.org/10.1075/tilar.15.06all

Ariel, M. (1990). Accessing noun-phrase antecedents. Routledge.

Arnold, J. E. (2008). Reference production: Production-internal and addressee-oriented processes. Language and Cognitive Processes, 23, 495-527.

https://doi.org/10.1080/01690960801920099

Arnold, J. E. (2010). How Speakers Refer: The Role of Accessibility. 4, 187-203.

Arnold, J. E., \& Griffin, Z. M. (2007). The effect of additional characters on choice of referring expression: everyone counts. Journal of Memory and Language, 56, 521-536. https://doi.org/10.1016/j.jml.2006.09.007

Arnold, J. E., \& Zerkle, S. A. (2019). Why do people produce pronouns? Pragmatic selection vs. rational models. Language, Cognition and Neuroscience, 34(9), 1152-1175. https://doi.org/10.108o/23273798.2019.1636103

Atkinson, M., Smith, K., \& Kirby, S. (2018). Adult learning and language simplification. Cognitive Science, 42, 2818-2854. https://doi.org/10.1111/cogs.12686

Aylett, M., \& Turk, A. (2004). The Smooth Signal Hypothesis: A functional explanation for relationships between redundancy, prosodic prominence, and duration in spontaneous speech. Language and Speech, 47(1), 31-56.

Bannon, J., Saryazdi, R., \& Chambers, C. G. (2020). Designing referential descriptions for children, young adults, and computers: a comprehensive examination of talker informativity. Proceedings of the 42nd Annual Conference of the Cognitive Science Society, 2957-2963.

Bard, E. G., Anderson, A. H., Sotillo, C., Aylett, M., Doherty-Sneddon, G., \& Newlands, A. (2000). Controlling the Intelligibility of Referring Expressions in Dialogue. Journal of Memory and Language, 42, 1-22. https://doi.org/10.1006/jmla.1999.2667 
Bard, E. G., \& Aylett, M. (2004). Referential form, word duration, and modeling the listener in spoken dialogue. In J. C. Trueswell \& M. K. Tanenhaus (Eds.), Approaches to Studying World-Situated Language Use: Bridging the Language-as-Product and Language-asAction Traditions (pp. 173-191). MIT Press.

Barr, D. J., Levy, R., Scheepers, C., \& Tily, H. J. (2013). Random effects structure for confirmatory hypothesis testing : Keep it maximal. Journal of Memory and Language, 68(3), 255-278. https://doi.org/10.1016/j.jml.2012.11.001

Bates, D., Mächler, M., Bolker, B. M., \& Walker, S. C. (2015). Fitting linear mixed-effects models using lme4. Journal of Statistical Software, 67, 1-48.

Bentz, C., Verkerk, A., Kiela, D., Hill, F., \& Buttery, P. (2015). Adaptive communication: Languages with more non-native speakers tend to have fewer word forms. PLoS ONE, 1O(6), 1-23. https://doi.org/10.1371/journal.pone.0128254

Bentz, C., \& Winter, B. (2013). Languages with more second language learners tend to lose nominal case. Language Dynamics and Change, 3, 1-27. https://doi.org/10.1163/22105832-13030105

Berman, R. A. (1988). On the ability to relate events in narratives. Discourse Processes, 11(4), $469-497$.

Berman, R. A., \& Slobin, D. I. (1994). Relating events in narrative: A crosslinguistic developmental study. Lawrence Erlbaum Associates.

Bortfeld, H., \& Brennan, S. E. (1997). Use and acquisition of idiomatic expressions in referring by native and non-native speakers. Discourse Processes, 23(2), 119-147. https://doi.org/10.1080/01638537709544986

Bortfeld, H., \& Morgan, J. L. (2010). Is early word-form processing stress-full? How natural variability supports recognition. Cognitive Psychology, 6o(4), 241-266. https://doi.org/10.1016/j.cogpsych.2010.01.002

Brennan, S. E. (1995). Centering attention in discourse. Language and Cognitive Processes, 
$10(2), 137-167$.

Brennan, S. E., \& Hanna, E. (2009). Partner-specific adaptation in dialog. Topics in Cognitive Science, 1, 274-291. https://doi.org/10.1111/j.1756-8765.2009.01019.x

Brown-Schmidt, S., Byron, D. K., \& Tanenhaus, M. K. (2005). Beyond salience: Interpretation of personal and demonstrative pronouns. Journal of Memory and Language, 53(2), 292-313. https://doi.org/10.1016/j.jml.2005.03.003

Buz, E., Tanenhaus, M. K., \& Jaeger, T. F. (2016). Dynamically adapted context-specific hyperarticulation: Feedback from interlocutors affects speakers 'subsequent pronunciations. Journal of Memory and Language, 89, 68-86. https://doi.org/10.1016/j.jml.2015.12.009

Chafe, W. L. (1976). Givenness, contrastiveness, definiteness, subjects, topics, and point of view. In C. N. Li (Ed.), Subject and topic (pp. 25-56). Academic Press.

Chafe, W. L. (1994). Discourse, consciousness, and time. Chicago University Press.

Clark, H. H., \& Murphy, G. L. (1983). Audience design in meaning and reference. In J. F. LeNy \& W. Kintsch (Eds.), Language and Comprehension (pp. 287-299). North-Holland Publishing Co.

Cohen Priva, U. (2015). Informativity affects consonant duration and deletion rates. Laboratory Phonology, 6(2), 243-278. https://doi.org/10.1515/lp-2015-0oo8

Dale, R., \& Lupyan, G. (2012). Understanding the origins of morphological diversity: the linguistic niche hypothesis. Advances in Complex Systems, 15(3), 1150017-1-1150017-16.

Durkin, K., Rutter, D. R., \& Tucker, H. (1982). Social interaction and language acquisition: motherese help you. First Language, 3, 107-120.

Ferguson, C. A. (1975). Toward a characterization of English foreigner talk. Anthropological Linguistics, 17(1), 1-14.

Fernald, A., \& Simon, T. (1984). Expanded intonation contours in mothers' speech to newborns. Developmental Psychology, 20(1), 104-113. https://doi.org/10.1037//o012-1649.20.1.104

Frank, A. F., \& Jaeger, T. F. (2008). Speaking Rationally : Uniform Information Density as an 
Optimal Strategy for Language Production. The 3oth Annual Meeting of the Cognitive Science Society, 939-944.

Frank, S., \& Smith, K. (2018). A model of linguistic accommodation leading to language simplification. Proceedings of the 4oth Annual Conference of the Cognitive Science Society.

Fukumura, K. (2015). Interface of linguistic and visual information during audience design. Cognitive Science, 39, 1419-1433. https://doi.org/10.1111/cogs.12207

Fukumura, K., \& Van Gompel, R. P. G. (2011). The effect of animacy on the choice of referring expression. Language and Cognitive Processes, 26(10), 1472-1504. https://doi.org/10.1080/01690965.2010.506444

Fukumura, K., \& Van Gompel, R. P. G. (2012). Producing pronouns and definite noun phrases: do speakers use the addressee's discourse model? Cognitive Psychology, 36, 1289-1311. https://doi.org/10.1111/j.1551-6709.2012.01255.x

Fukumura, K., Van Gompel, R. P. G., Harley, T., \& Pickering, M. J. (2011). How does similaritybased interference affect the choice of referring expression? Journal of Memory and Language, 65, 331-344. https://doi.org/10.1016/j.jml.2011.06.001

Fukumura, K., Van Gompel, R. P. G., \& Pickering, M. J. (2010). The use of visual context during the production of referring expressions. Quarterly Journal of Experimental Psychology, 63(9), 1700-1715. https://doi.org/10.1080/17470210903490969

Gibson, E., Futrell, R., Piandadosi, S. T., Dautriche, I., Mahowald, K., Bergen, L., \& Levy, R. (2019). How Efficiency Shapes Human Language. Trends in Cognitive Sciences, 23(5), 389-407. https://doi.org/10.1016/j.tics.2019.02.003

Givón, T. (1983). Topic continuity in discourse: an introduction. In T. Givón (Ed.), Topic continuity in discourse: A quantitativecross-language study (pp. 1-42). John Benjamins.

Grice, H. P. (1975). Logic and conversation. In P. Cole \& J. Morgan (Eds.), Syntax and Semantics, vol. 3 (pp. 41-58). Academic Press. 
Grosz, B. J., Joshi, A. K., \& Weinstein, S. (1995). Centering: a framework for modeling the local coherence of discourse. Computational Linguistics - Association for Computational Linguistics, 21(2), 203-225.

Guerriero, A. M. S., Oshima-Takane, Y., \& Kuriyama, Y. (2006). The development of referential choice in English and Japanese: A discourse-pragmatic perspective. Journal of Child Language, 33(4), 823-857. https://doi.org/10.1017/So30500090600763X

Gundel, J. K., Hedberg, N., \& Zacharski, R. (1993). Cognitive status and the form of referring expressions in discourse. Language, 69(2), 274-307.

Heller, D., Gorman, K. S., \& Tanenhaus, K. (2012). To name or to describe: shared knowledge affects referential form. Topics in Cognitive Science, 4, 290-305. https://doi.org/10.1111/j.1756-8765.2012.01182.x

Hughes, M. E., \& Allen, S. E. M. (2013). The effect of individual discourse-pragmatic features on referential choice in child English. Journal of Pragmatics, 56(1), 15-30. https://doi.org/10.1016/j.pragma.2013.05.005

Hughes, M. E., \& Allen, S. E. M. (2015). The incremental effect of discourse-pragmatic sensitivity on referential choice in the acquisition of a first language. Lingua, 155, 43-61. https://doi.org/10.1016/j.lingua.2014.03.001

Hyams, N. (2008). Reflections on Motherese. In T. Sano, M. Endo, M. Isobe, K. Otaki, K. Sugisaki, \& T. Suzuki (Eds.), An enterprise in the cognitve science of language (pp. 1-12). Hituzu Syobo Publishing.

Isaacs, E. A., \& Clark, H. H. (1987). References in conversation between experts and novices. Journal of Experimental Psychology, 116(1), 26-37.

Jaeger, T. F. (2010). Redundancy and reduction: Speakers manage syntactic information density. Cognitive Psychology, 61(1), 23-62. https://doi.org/10.1016/j.cogpsych.2010.02.002

Jaeger, T. F., \& Buz, E. (2017). Signal Reduction and Linguistic Encoding. In E. Fernández \& H. 
Cairns (Eds.), The Handbook of Psycholinguistics (pp. 38-81). John Wiley \& Sons.

Kravtchenko, E. (2014). Predictability and syntactic production: Evidence from subject omission in Russian. Proceedings of the 36th Annual Conference of the Cognitive Science Society, 785-79o. http://people.ucsc.edu/ ekravtch/Kravtchenko_CogSci2014.pdf

Kurumada, C., \& Jaeger, T. F. (2015). Communicative efficiency in language production: optional case-marking in Japanese. Journal of Memory and Language, 83, 152-178. https://doi.org/10.1016/j.jml.2015.03.003

Lambrecht, K. (1994). Information structure and sentence form: Topic, focus, and the mental representations of discourse referents. Cambridge University Press.

Levy, R., \& Jaeger, T. F. (2007). Speakers optimize information density through syntactic reduction. In B. Schlökopf, J. Platt, \& T. Hoffman (Eds.), Advances in neural information processing systems (NIPS) 19 (pp. 849-856). MIT Press.

Lieberman, P. (1963). Some effects of semantic and grammatical context on the production and perception of speech. Language and Speech, 6, 172-187.

Lockridge, C. B., \& Brennan, S. E. (2002). Addressees' needs influence speakers' early syntactic choices. Psychonomic Bulletin \& Review, 9(3), 550-557.

Lombard, E. (1911). Le signe de l'elevation de la voix. Annales de Maladies de L'oreille et $\mathrm{Du}$ Larynx, 37, 101-119.

Long, M. H. (1983). Linguistic and conversational adjustments to non native speakers. Studies in Second Language Acquisition, 5, 177-193.

Loy, J. E., Bloomfield, S. J., \& Smith, K. (2020). Effects of priming and audience design on the explicitness of referring expressions: evidence from a confederate priming paradigm. Discourse Processes, 57(9), 808-821. https://doi.org/10.1080/0163853X.2020.1802192

Loy, J. E., \& Smith, K. (2020). Syntactic adaptation may depend on perceived linguistic knowledge: Native English speakers differentially adapt to native and nonnative confederates in dialogue. https://doi.org/10.31234/osf.io/pu2qa 
Lupyan, G., \& Dale, R. (2010). Language structure is partly determined by social structure. PLoS ONE, 5(1). https://doi.org/10.1371/journal.pone.ooo8559

Mahowald, K., Fedorenko, E., Piantadosi, S. T., \& Gibson, E. (2013). Info/information theory: Speakers choose shorter words in predictive contexts. Cognition, 126(2), 313-318. https://doi.org/10.1016/j.cognition.2012.09.010

Mayer, M. (1969). Frog, where are you? Dial Press.

Miller, J. F., Heilmann, J., Nockerts, A., Iglesias, A., Fabiano, L., \& Francis, D. J. (2006). Oral language and reading in bilingual children. Learning Disabilities Research \& Practice, 21(1), 30-43.

Orita, N., Vornov, E., Feldman, N. H., \& Daumé III, H. (2015). Why discourse affects speakers' choice of referring expressions. Proceedings of ACL-IJCNLP, 1639-1649.

Pate, J. K., \& Goldwater, S. (2015). Talkers account for listener and channel characteristics to communicate efficiently. Journal of Memory and Language, 78, 1-17.

Piantadosi, S. T., Tily, H., \& Gibson, E. (2011a). The communicative function of ambiguity in language. Cognition, 122(3), 280-291. https://doi.org/10.1016/j.cognition.2011.10.004

Piantadosi, S. T., Tily, H., \& Gibson, E. (2011b). Word lengths are optimized for efficient communication. Proceedings of the National Academy of Sciences of the United States of America, 108(9), 3526-3529. https://doi.org/10.1073/pnas.1012551108

Ramamurti, R. (1980). Strategies Involved in Talking to a Foreigner. PENN Review of Linguistics, 4, 84-93.

Roche, J. M., Paxton, A., Ibarra, A., \& Tanenhaus, M. K. (2013). From minor mishap to major catastrophe: lexical choice in miscommunication. In M. Knauff, M. Pauen, N. Sebanz, \& I. Wachsmuth (Eds.), Proceedings of the Annual Meeting of the Cognitive Science Society (pp. 3303-3308).

Rodriguez-Cuadrado, S., Baus, C., \& Costa, A. (2017). Foreigner talk through word reduction in native/non-native spoken interactions. Bilingualism: Language and Cognition, 1-8. 
https://doi.org/10.1017/S1366728917000402

Rohde, H., \& Frank, M. C. (2014). Markers of Topical Discourse in Child-Directed Speech. Cognitive Science, 38, 1634-1661. https://doi.org/10.1111/cogs.12121

Rohde, H., \& Kehler, A. (2014). Grammatical and information-structural influences on pronoun production. Language, Cognition and Neuroscience, 29(8), 912-927. https://doi.org/10.1080/01690965.2013.854918

Rosa, E. C., \& Arnold, J. E. (2017). Predictability affects production: Thematic roles can affect reference form selection. Journal of Memory and Language, 94, 43-60. https://doi.org/10.1016/j.jml.2016.07.007

Rosa, E. C., Finch, K. H., Bergeson, M., \& Arnold, J. E. (2015). The effects of addressee attention on prosodic prominence. Language, Cognition and Neuroscience, 3o(1-2), 48-56. https://doi.org/10.1080/01690965.2013.772213

Summers, W. Van, Pisoni, D. B., Bernacki, R. H., Pedlow, R. I., \& Stokes, Michael, A. (1988). Effects of noise on speech production: acoustic and perceptual analyses. The Journal of the Acoustical Society of America, 84(3), 917-928.

Tal, S., \& Arnon, I. (2018). SES effects on the use of variation sets in child-directed speech. Journal of Child Language, 45(6), 1423-1438. https://doi.org/10.1017/So305000918000223

Tal, S., Grossman, E., \& Arnon, I. (2021). Infant-directed speech becomes less redundant as infants grow: implications for language learning. https://psyarxiv.com/bgtzd/

Tily, H., \& Piantadosi, S. (2009). Refer efficiently: Use less informative expressions for more predictable meanings. Proceedings of the Workshop on the Production of Referring Expressions: Bridging the Gap between Computational and Empirical Approaches to Reference.

Tippenhauer, N., Fourakis, E. R., Watson, D. G., \& Lew-Williams, C. (2020). The scope of audience design in child-directed speech: parents' tailoring of word lengths for adult versus 
child listeners. Journal of Experimental Psychology: Learning, Memory, and Cognition, 46(11), 2163-2178. https://doi.org/10.1017/CBO9781107415324.004

Trudgill, P. (2009). Sociolinguistic typology and complexification. In P. Trudgill, G. Sampson, \& D. Gil (Eds.), Language Complexity as an Evolving Variable (pp. 98-109). Oxford University Press.

Uther, M., Knoll, M. A., \& Burnham, D. (2007). Do you speak E-NG-L-I-SH ? A comparison of foreigner- and infant-directed speech. Speech Communication, 49, 2-7. https://doi.org/10.1016/j.specom.2006.10.003

Van der Meulen, F. F., Meyer, A. S., \& Levelt, W. J. M. (2001). Eye movements during the production of nouns and pronouns. Memory and Cognition, 29(3), 512-521. https://doi.org/10.3758/BFo3196402

Van Engen, K. J., Baese-Berk, M., Baker, R. E., Choi, A., Kim, M., \& Bradlow, A. R. (2010). The wildcat corpus of native-and foreign-accented english: communicative efficiency across conversational dyads with varying language alignment profiles. Language and Speech, 53(4), 510-540. https://doi.org/10.1177/0023830910372495

Velupillai, V. (2012). An introduction to linguistic typology. John Benjamins.

Vogels, J., Krahmer, E., \& Maes, A. (2015). How cognitive load influences speakers' choice of referring expressions. Cognitive Science, 39(6), 1396-1418. https://doi.org/10.1111/cogs.12205

Waterfall, H. (2006). A little change is a good thing: feature theory, language acquisition and variation sets (Doctoral dissertation). University of Chicago.

Werker, J. F., Pegg, J. E., \& McLeod, P. J. (1994). A cross-language investigation of infant preference for infant-directed communication. Infant Behavior and Development, 17(3), 323-333. https://doi.org/10.1016/0163-6383(94)90012-4

Wooldridge, B. (2001). "Foreigner talk": an important element in cross-cultural management education and training. International Review of Administrative Sciences, 67(4), 621-634. 
Wray, A., \& Grace, G. W. (2007). The consequences of talking to strangers: evolutionary corollaries of socio-cultural influences on linguistic form. Lingua, 117, 543-578. https://doi.org/10.1016/j.lingua.2005.05.005

Zhao, Y., \& Jurafsky, D. (2009). The effect of lexical frequency and Lombard reflex on tone hyperarticulation. Journal of Phonetics, 37, 231-247. https://doi.org/10.1016/j.wocn.2009.03.002

Zipf, G. K. (1949). Human behavior and the principle of least effort: An introduction to human ecology. Addison-Wesley Press. 


\section{Table 1.}

Example references with different types of previous mention statuses. In each example the reference at question is underlined.

Pronoun NP

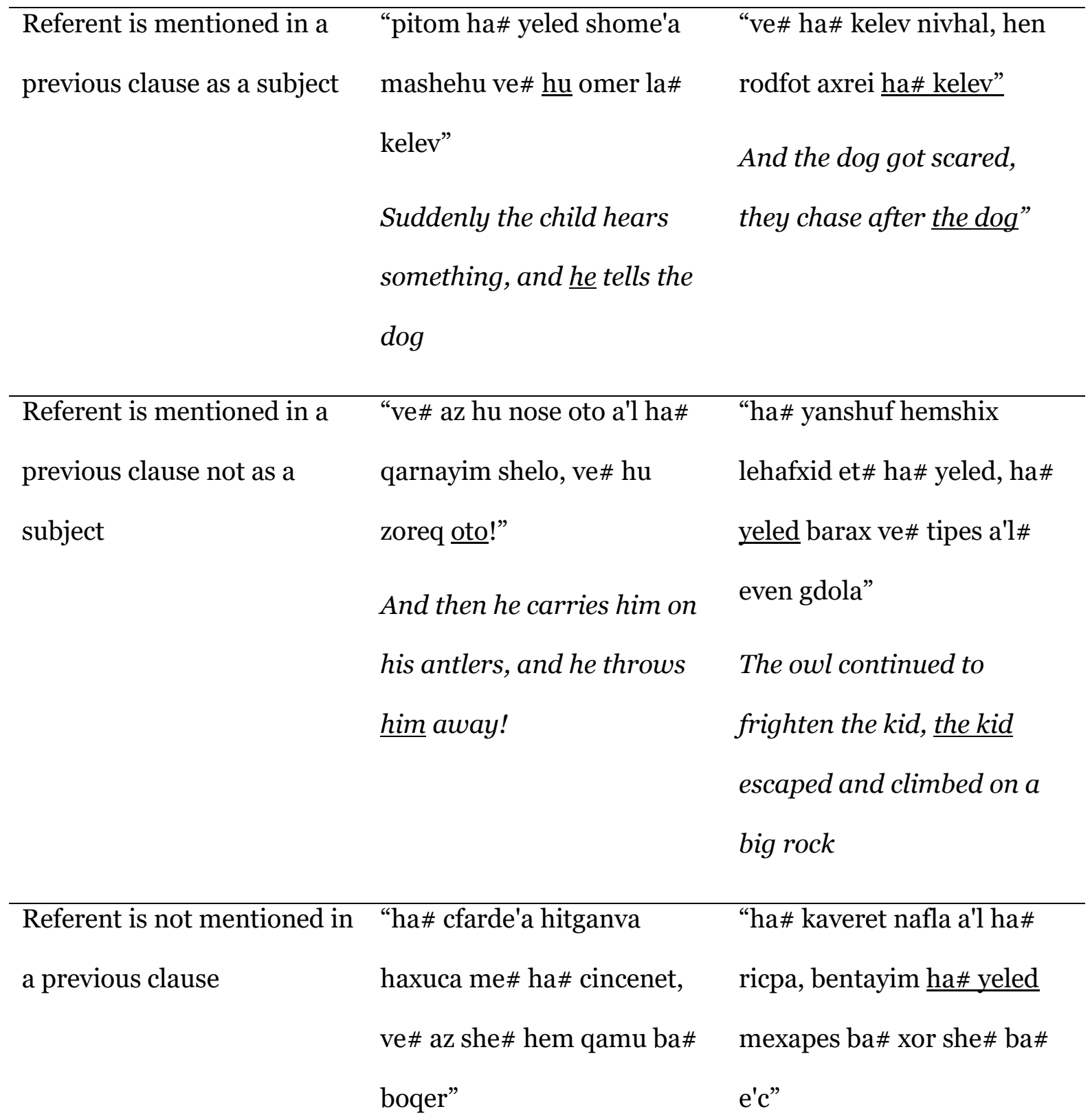




$\begin{array}{ll}\text { The frog sneaked out of the } & \text { The beehive fell on the floor, } \\ \text { jar, and then they woke up } & \text { in the meantime the boy is } \\ \text { in the morning } & \text { searching in a hole in a tree }\end{array}$


Table 2.

Summary of the regression model of references used in the child-learner study, using the two-level coding scheme for previous mentions

\begin{tabular}{cccccc}
\hline & Estimate & Std. Error & z-value & p-value & Odds ratio \\
\hline Intercept & -0.72 & 0.121 & -5.96 & $<.001^{* * *}$ & 0.487 \\
Age & -0.023 & 0.01 & -2.352 & $0.019^{*}$ & 0.977 \\
$\begin{array}{c}\text { Previos mention } \\
\text { status=new }\end{array}$ & 0.831 & 0.087 & 9.563 & $<.001 * * *$ & 2.295 \\
Character = boy & 0.04 & 0.093 & 0.432 & 0.666 & 1.041 \\
$\begin{array}{c}\text { Character = boy\&dog } \\
\text { Age * Previous }\end{array}$ & -1.42 & 0.133 & -10.66 & $<.001 * * *$ & 0.242 \\
mention status=new & -0.013 & 0.008 & -1.708 & 0.088 & 0.987
\end{tabular}




\section{Table 3.}

Summary of the regression model of references used in the child-learner study, using the three-level coding scheme for previous mentions

\begin{tabular}{|c|c|c|c|c|c|}
\hline & Estimate & Std. Error & z-value & p-value & Odds ratio \\
\hline Intercept & -0.913 & 0.131 & -6.971 & $<.001 * * *$ & 0.401 \\
\hline Age & -0.023 & 0.011 & -2.027 & $0.043 *$ & 0.977 \\
\hline $\begin{array}{c}\text { Previous mention } \\
\text { status }=\text { mentioned not } \\
\text { as subject }\end{array}$ & -0.083 & 0.138 & -0.6 & 0.549 & 0.92 \\
\hline $\begin{array}{c}\text { Previous mention } \\
\text { status }=\text { mentioned as } \\
\text { subject }\end{array}$ & -0.923 & 0.114 & -8.105 & $<.001 * * *$ & 0.397 \\
\hline Character $=$ boy & 0.052 & 0.093 & 0.562 & 0.574 & 1.054 \\
\hline Character $=$ boy\&dog & -1.458 & 0.133 & -10.967 & $<.001 * * *$ & 0.233 \\
\hline $\begin{array}{c}\text { Age } * \text { Previous mention } \\
\text { status }=\text { mentioned not } \\
\text { as subject }\end{array}$ & -0.012 & 0.015 & -0.801 & 0.423 & 0.988 \\
\hline $\begin{array}{c}\text { Age } * \text { Pre mention } \\
\text { status }=\text { mentioned as } \\
\text { subject }\end{array}$ & 0.026 & 0.011 & 2.339 & $0.019 *$ & 1.027 \\
\hline
\end{tabular}


Table 4.

Summary of the regression model of references used in the adult-learner study, using the two-level coding scheme for previous mentions

\begin{tabular}{cccccc}
\hline & Estimate & Std. Error & z-value & p-value & Odds ratio \\
\hline $\begin{array}{c}\text { Intercept } \\
\text { Condition = Proficient } \\
\text { speaker }\end{array}$ & -0.462 & 0.108 & -4.261 & $<.001^{* * *}$ & 0.63 \\
$\begin{array}{c}\text { Previous mention } \\
\text { status=new }\end{array}$ & -0.243 & 0.105 & -2.314 & $0.021^{*}$ & 0.784 \\
$\quad$ Character = boy & 0.246 & 0.075 & 16.667 & $<.001^{* * *}$ & 3.476 \\
$\begin{array}{c}\text { Character = boy\&dog } \\
\begin{array}{c}\text { Condition = Proficient } \\
\text { speaker * Previous }\end{array}\end{array}$ & -1.84 & 0.083 & 3.599 & $<.001^{* * *}$ & 1.35 \\
mention status=new & -0.041 & 0.071 & -0.583 & 0.56 & 0.159
\end{tabular}




\section{Table 5.}

Summary of the regression model of references used in the adult-learner study, using the three-level coding scheme for previous mentions

\begin{tabular}{|c|c|c|c|c|c|}
\hline & Estimate & Std. Error & z-value & p-value & Odds ratio \\
\hline Intercept & -0.872 & 0.115 & -7.612 & $<.001 * * *$ & 0.418 \\
\hline $\begin{array}{c}\text { Condition }=\text { Proficient } \\
\text { speaker }\end{array}$ & -0.235 & 0.112 & -2.097 & $0.036 *$ & 0.791 \\
\hline $\begin{array}{c}\text { Previous mention } \\
\text { status }=\text { mentioned not as } \\
\text { subject }\end{array}$ & -0.565 & 0.13 & -4.362 & $<.001 * * *$ & 0.568 \\
\hline $\begin{array}{l}\text { Previous mention status }= \\
\text { mentioned as subject }\end{array}$ & -1.025 & 0.105 & -9.802 & $<.001 * * *$ & 0.359 \\
\hline Character $=\operatorname{dog}$ & 0.359 & 0.083 & $4 \cdot 347$ & $<.001 * * *$ & 1.432 \\
\hline Character $=$ boy\&dog & -1.921 & 0.102 & -18.815 & $<.001^{* * *}$ & 0.146 \\
\hline $\begin{array}{c}\text { Condition }=\text { Proficient } \\
\text { speaker } * \text { Previous } \\
\text { mention status=mentioned } \\
\text { not as subject }\end{array}$ & 0.015 & 0.128 & 0.121 & 0.904 & 1.016 \\
\hline $\begin{array}{l}\text { Condition }=\text { Proficient } \\
\text { speaker } * \text { Previous } \\
\text { mention status }= \\
\text { mentioned as subject }\end{array}$ & 0.022 & 0.104 & 0.207 & 0.836 & 1.022 \\
\hline
\end{tabular}


Figure 1

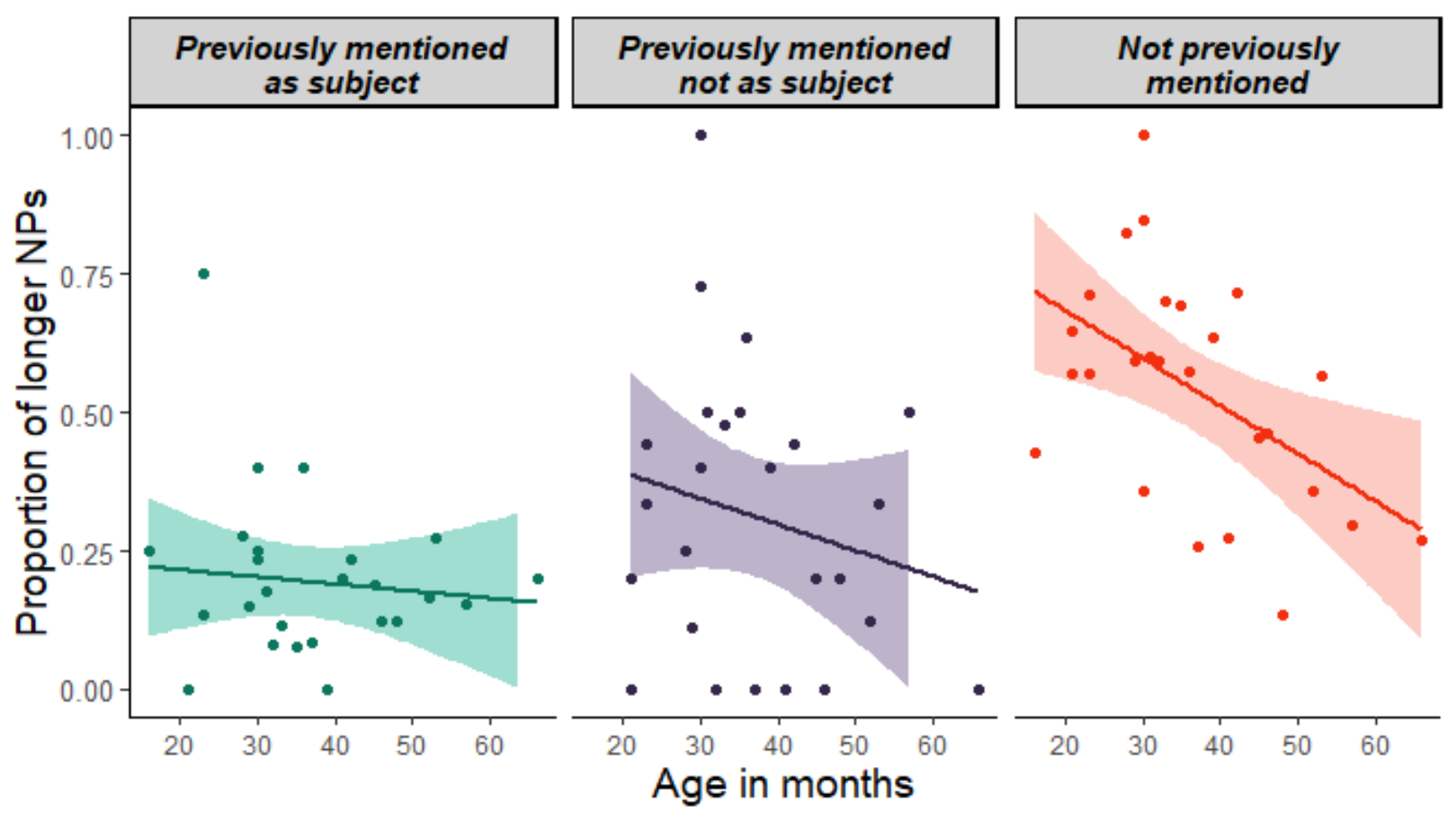


Figure 2

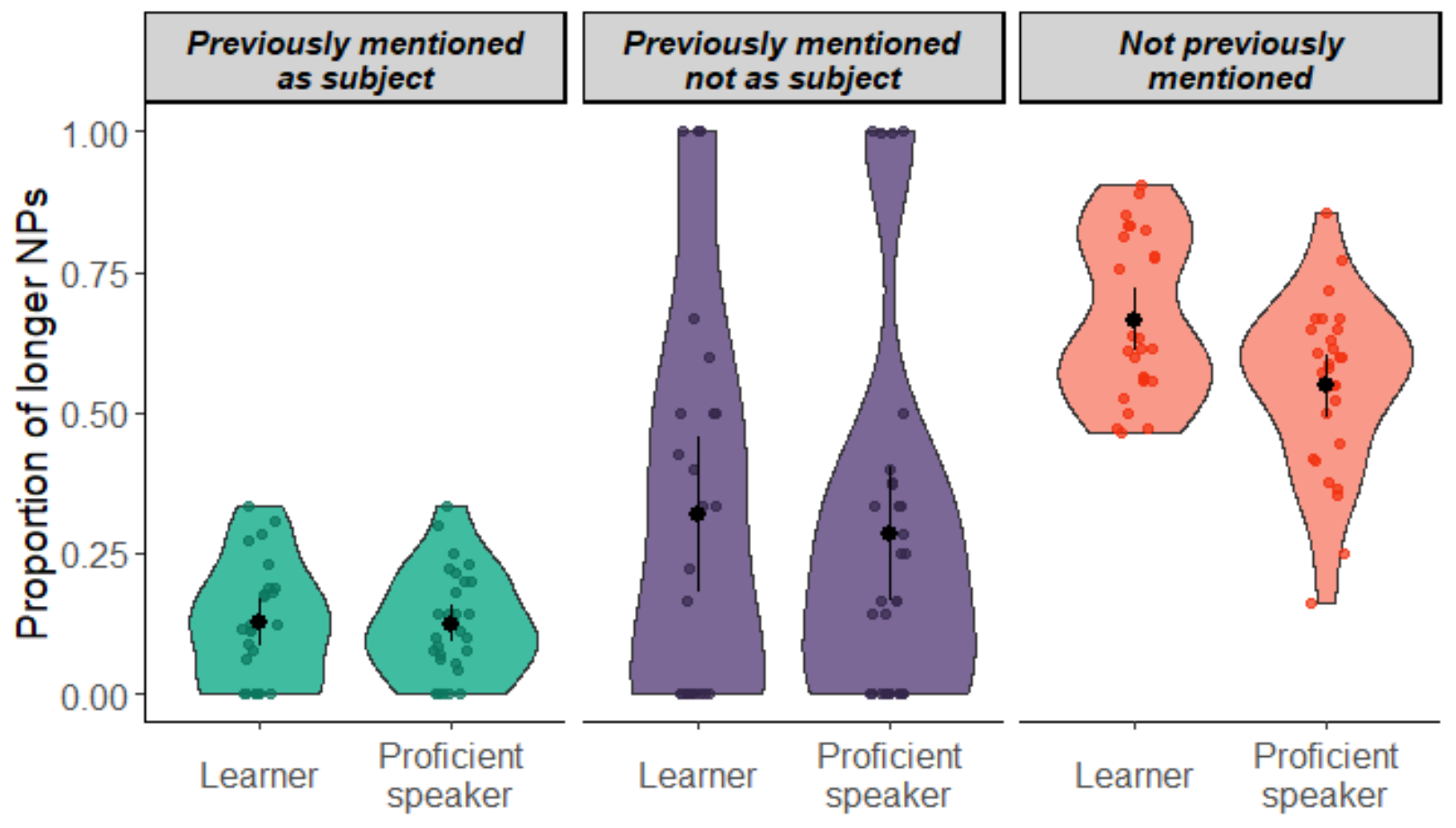




\section{Figure 1}

Proportion of longer NPs (as opposed to pronouns) by age (in months) and previous mention status (according to the three-level coding scheme). Each dot represents a speaker.

\section{Figure 2}

Proportion of longer NPs (as opposed to pronouns) by condition and previous mention status (according to the three-level coding scheme). Each dot represents a speaker; error bars indicate confidence intervals of $95 \%$. 